\title{
Adaptation Learning Control for a H-P Induction Motor using Neural Networks
}

\author{
Mokhtar ZERIKAT and Soufyane CHEKROUN \\ Department of Electrical and Computer Engineering, Laboratory of Automatic and \\ Analysis Systems, Higher School of ENSET, Oran-Algeria \\ Mokhtar.zerikat@enset-oran.dz, schekroun@hotmail.fr
}

\section{Introduction}

AC induction motors are very popular in variable speed drives. They are simple rugged, inexpensive and available at all power ratings. Progress in the field of power electronics and microelectronics enables the application of induction motors for high performance drives, where traditionally only DC motors were applied (Liaw, et al. 1991). Thanks to sophisticated control methods, AC induction drives, where sophistically control methods, AC induction drives offer the same control capabilities as high performance four quadrant DC drives. The induction motors it is desirable to control the flux and torque separately in order to have the same performances as those of DC motors. One way of doing this is by using the field oriented control (Zhang, Thiagarajan et al. 1988). This method assures the decoupling of flux and torque. The Vector-controlled induction motors with a conventional PI speed controller. On of the most noticeable control theories is the method using the Adaptive Neural Network (Tien-Chi and Tsong-Terng, 2002; Oh and cho. et al. 2006). Adaptive Neural Network can approximate linear or non linear functions is used extensively in industry (Pillay and Krishnam, 1988), because the conventional PI controller is easily implemented. Many theories for the non linear system control have been proposed to solve the problems of the conventional control method through learning. Compared with existing control method, it does not require complex mathematical calculation or models needed for obtaining system parameters and it can success fully control non linear system. In the following section, we explain a vector control of the induction motor in section 2 . Section 3 describes the structure of the proposed neural control scheme. The obtain simulation results are shown discussion in section 4 . Finally, conclusion is made in section 5.

\section{Vector control of the induction motor}

\subsection{Mathematical Modeling of Induction motor}

"Figure 1" shows the real, stationary and synchronously rotating axes of a 3 phase symmetrical induction motor. It has been used to describe the induction motor mathematical model, based on the vector method. (Chen and Sheu, 1999). 


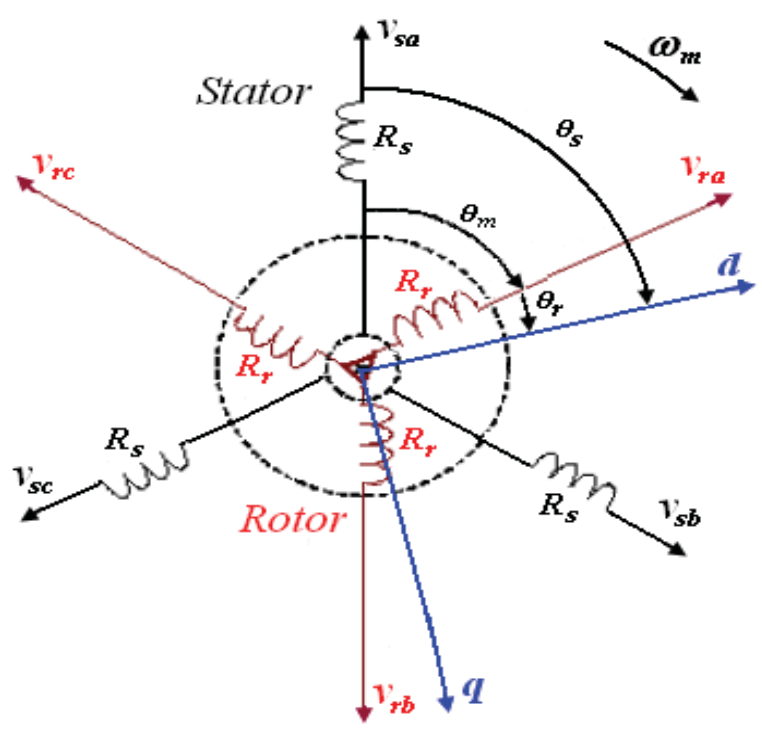

Fig. 1. Space vector with $a, b, c$ and $d, q$ axis

where s,r denote stator and rotor. a,b,c are the phase system axis. $\mathrm{d}$ and $\mathrm{q}$ denote direct and quadratic components of the vectors with respect to the fixed stator reference $d, q$. Thus the slip angle $\theta_{\mathrm{s}}$ can be calculated as the time integral of the slip angle velocity $\omega_{\mathrm{s}}$, by adding the rotor angle $\theta_{\mathrm{r}}$ to the slip angle the rotor flux position $\theta_{\mathrm{m}}$, many be calculated (1):

$$
\theta_{\mathrm{s}}=\theta_{\mathrm{r}}+\theta_{\mathrm{m}}
$$

The mathematical model of induction motor applied in the paper, has been obtained after the transformation of the stator and the rotor phase equations into two, rotating with synchronous velocity $\omega_{\mathrm{s}}$ orthogonal axes (2),(3).

$$
\begin{aligned}
& \frac{\mathrm{d}}{\mathrm{dt}} \mathrm{i}_{\mathrm{sd}}= \frac{1}{\sigma \cdot \mathrm{L}_{\mathrm{s}}}\left[-\left(\mathrm{R}_{\mathrm{s}}+\frac{\mathrm{M}^{2} \mathrm{R}_{\mathrm{r}}}{\mathrm{L}_{\mathrm{r}}^{2}}\right) \cdot \mathrm{i}_{\mathrm{sd}}+\omega_{\mathrm{s}} \cdot \sigma \cdot \mathrm{L}_{\mathrm{s}} \cdot \mathrm{i}_{\mathrm{sq}}+\frac{\mathrm{MR}_{\mathrm{r}}}{\mathrm{L}_{\mathrm{r}}^{2}} \cdot \psi_{\mathrm{rd}}\right. \\
&+\frac{\mathrm{M}}{\mathrm{L}_{\mathrm{r}}} \cdot \omega_{\mathrm{r}} \cdot \psi_{\mathrm{rq}}+\mathrm{u}_{\mathrm{sd}} \\
& \frac{\mathrm{d}}{\mathrm{dt}} \mathrm{i}_{\mathrm{sq}}= \frac{1}{\sigma \cdot \mathrm{L}_{\mathrm{s}}}\left[-\omega_{\mathrm{s}} \cdot \sigma \cdot \mathrm{L}_{\mathrm{s}} \cdot \mathrm{i}_{\mathrm{sd}}-\left(\mathrm{R}_{\mathrm{s}}+\frac{\mathrm{M}^{2}}{\mathrm{~L}_{\mathrm{r}} \cdot \mathrm{T}_{\mathrm{r}}}\right) \cdot \mathrm{i}_{\mathrm{sq}}-\frac{\mathrm{M}}{\mathrm{L}_{\mathrm{r}}} \omega_{\mathrm{r}} \cdot \psi_{\mathrm{rd}}\right. \\
&+\frac{\mathrm{M}}{\mathrm{L}_{\mathrm{r}} \cdot \mathrm{T}_{\mathrm{r}}} \cdot \psi_{\mathrm{rq}}+\mathrm{u}_{\mathrm{sq}} \\
& \begin{cases}\frac{\mathrm{d}}{\mathrm{dt}} \psi_{\mathrm{rd}}= & \frac{\mathrm{MR}}{\mathrm{L}_{\mathrm{r}}} \cdot \mathrm{i}_{\mathrm{sd}}-\frac{\mathrm{R}_{\mathrm{r}}}{\mathrm{L}_{\mathrm{r}}} \cdot \psi_{\mathrm{rd}}+\left(\omega_{\mathrm{s}}-\omega_{\mathrm{r}}\right) \cdot \psi_{\mathrm{rq}} \\
\frac{\mathrm{d}}{\mathrm{dt}} \psi_{\mathrm{rq}}=\frac{\mathrm{MR}_{\mathrm{r}}}{\mathrm{L}_{\mathrm{r}}} \cdot \mathrm{i}_{\mathrm{sq}}-\left(\omega_{\mathrm{s}}-\omega_{\mathrm{r}}\right) \cdot \psi_{\mathrm{rd}}-\frac{\mathrm{R}_{\mathrm{r}}}{\mathrm{L}_{\mathrm{r}}} \cdot \psi_{\mathrm{rq}}\end{cases}
\end{aligned}
$$




$$
\sigma=1-\frac{\mathrm{M}^{2}}{\mathrm{~L}_{\mathrm{s}} \mathrm{L}_{\mathrm{r}}}
$$

where i, $u, \Psi$ denote current, voltage and flux linkage respectively. Subscripts $r$ and s stand for rotor and stator. $\omega_{\mathrm{r}}$ is the rotor speed, $\mathrm{L}$ and $\mathrm{R}$ are the auto-inductances and resistances, $\mathrm{M}$ is the mutual inductance. $\sigma$ constant coefficient. The motor load system can be described by a fundamental torque equation (4):

$$
\mathrm{T}=\mathrm{T}_{1}+\mathrm{J} \frac{\mathrm{d} \Omega_{\mathrm{m}}}{\mathrm{dt}}+\mathrm{f} \Omega_{\mathrm{m}}=\frac{\mathrm{n}_{\mathrm{p}} \mathrm{M}}{\mathrm{L}_{\mathrm{r}}}\left(\psi_{\mathrm{rd}} \mathrm{i}_{\mathrm{sq}}-\psi_{\mathrm{rq}} \mathrm{i}_{\mathrm{sd}}\right)
$$

where $\mathrm{T}$ the instantaneous value of the developed motor torque. $\mathrm{T}_{1}$ the instantaneous value of the load torques. $\Omega_{\mathrm{m}}$ rotor speed of the motor shaft. J the moment of inertia of the motor load system. $f$ the coefficient of frotement. $n_{p}$ the number of pair poles.

\subsection{Indirect Vector Control of Induction Motor}

Based on reference frame theory, the induction motor drive can be controlled like a separately exited dc machine by field oriented control method (Liaw et al. 1991), which can be design in tow basic ways by direct or indirect method. The choice between these two methods is not obvious because each method has its distinctive advantages and disadvantages. As a result a great research effort has been made to improve both direct and indirect field oriented controllers by design of complicated hardware and software to compensate non-ideal machine behaviour such as parameter variations due to temperature changes, rotor deep bar effects and magnetic saturation. The bloc diagram shown in "Figure 2", depicts the general structure of the indirect field oriented control with speed control motor drive, has been chosen for control of induction motor drive.

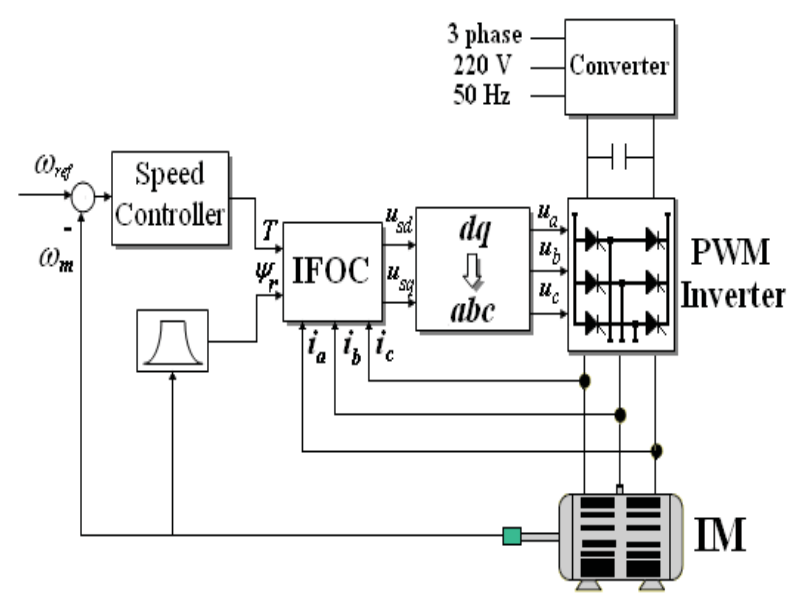

Fig. 2. Indirect field oriented induction motor drive 
This scheme includes induction motor, pulse with modulated (PWM) inverter, indirect field oriented control (IFOC) and speed controller. In this approach the flux angle $\theta_{\mathrm{s}}$ is not measured directly, but is estimated from the equivalent circuit model and from measurements of the rotor speed, stator currents, and the voltages $\mathrm{u}_{\mathrm{sd}}, \mathrm{u}_{\mathrm{sq}}$.

\subsection{PI Speed Controller}

The dynamic model of speed induction motor drive is significantly simplified, and can be reasonably represented by the bloc diagram shown in "Figure 3".

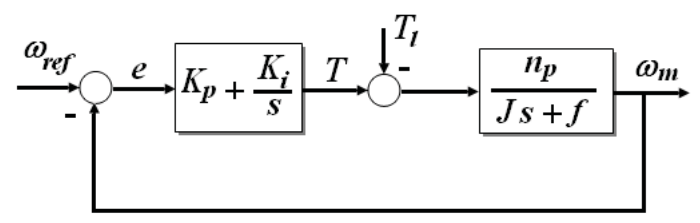

Fig. 3. Bloc diagram of speed system controller.

By using the Laplace transformation, the transfer function for (4) is equation (5):

$$
\omega_{\mathrm{m}}(\mathrm{s})=\frac{\mathrm{n}_{\mathrm{p}}\left(\mathrm{T}-\mathrm{T}_{1}\right)}{\mathrm{Js}+\mathrm{f}}
$$

The PI controller (Proportional and Integral) is used during the start up transition to increase the speed of the transient response. It also is well suited to regulating the torque, to the desired values as it is able to reach constant reference, by correctly both the $\mathrm{P}$ term $\left(\mathrm{K}_{\mathrm{p}}\right)$ and I term $\left(\mathrm{K}_{\mathrm{i}}\right)$ winches are respectively responsible for error e sensibility and for the steady state error. If $\mathrm{T}_{1}=0$, the transfer function is as following (6),(7):

$$
G(s)=\frac{n_{p}\left(K_{p} s+K_{i}\right)}{J s^{2}+\left(f+K_{p} n_{p}\right) s+K_{i} n_{p}}
$$

Where

$$
P(s)=s^{2}+\frac{f+K_{p} n_{p}}{J} s+\frac{K_{i} n_{p}}{J}=0
$$

The expressions for $K_{p}$ and $K_{i}$ of the regulator is calculated by Imposition of poles complexes combined with real part negative (8)

$$
S_{1,2}=\rho(-1 \pm j)
$$




$$
\left\{\begin{array}{c}
K_{p}=\frac{2 \rho^{2}-f}{n_{p}} \\
K_{i}=\frac{2 J \rho^{2}}{n_{p}}
\end{array}\right.
$$

where $\rho$ It is a positive constant.

The proposed indirect vector control has several advantages over conventional one as are its independence of the motor model parameters and simple microcomputer implementation. The effects of stator resistance $R_{r}$ variations in the calculation of slip frequency and transformation angle is compensated by motion controller. The nonlinearities caused by magnetic saturation can be compensated by the inverse magnetizing characteristic.

\section{Control system based artificial Neural Network}

\subsection{Adaptive Neural Networks}

A general architecture graph of Multilayer Perceptron (MLP) is shown in "Figure 4". This network which can be multiplexed for each output of the controller has been found to possess acceptable performance in many industrial applications. The feed-forward topology shown in the network of "Figure 4", offers the advantage of simplicity and ease programming. Such a neural network contains three layer, hidden layers and output layer. Each layer is composed of several neurons. The number of the neurons in the output and layers depends on the number of the selected input and output variables. The number of hidden layers and the number of neurons in each depend on the system dynamic and the desired degree of accuracy.

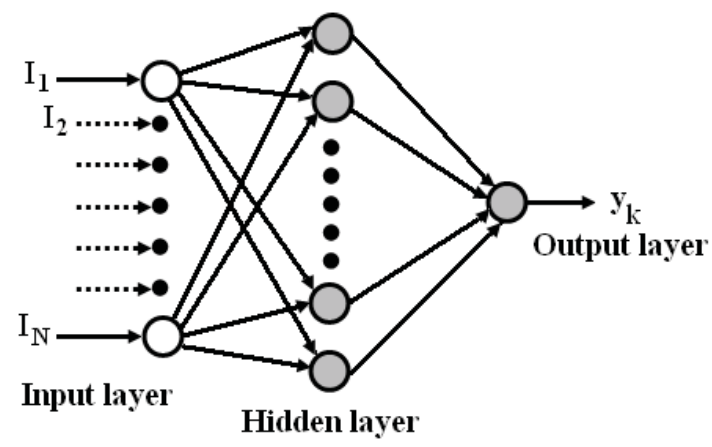

Fig. 4. Architecture of Multilayer Neural Network

The block-diagram of "Figure 5". Shows the model of a neuron, which performs two functions. The fist is to sum all the inputs from the upper layer based on their weighting factors in equation (9). The second is to process this sum by a nonlinear sigmoidal function in equation (10). 


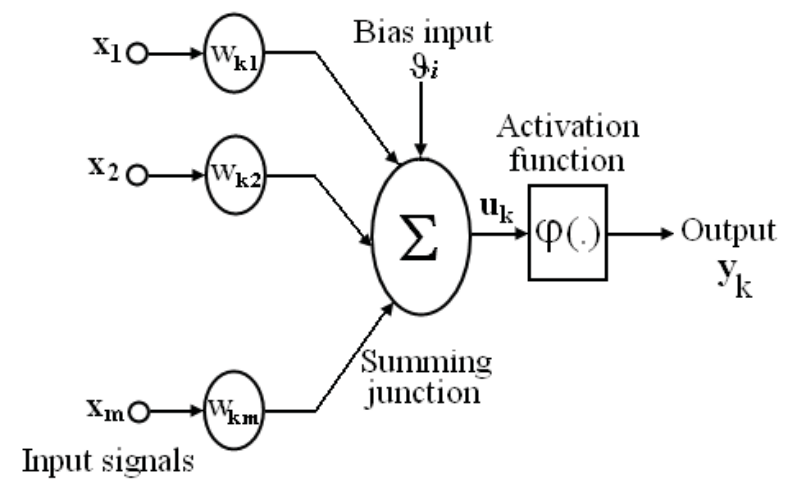

Fig. 5. Basic model of formal neurone

The basic equations describing the dynamics of each neuron are (9),(10) :

$$
\begin{gathered}
\mathrm{u}_{\mathrm{k}}=\sum_{\mathrm{j}=1}^{\mathrm{m}} \mathrm{w}_{\mathrm{ji}} \mathrm{x}_{\mathrm{j}} \\
\mathrm{y}_{\mathrm{k}}=\phi\left(\mathrm{u}_{\mathrm{j}}+\mathrm{v}_{\mathrm{j}}\right)
\end{gathered}
$$

Where $\mathrm{w}_{\mathrm{ji}}$ design the synaptic weight between the jth neuron and the ith neuron in two adjacent layers. $\varphi($.$) is the activation function. The neural network has two phases of$ operations, training and testing. In the training phase, the weights of the neural network are adjusted to map the input of the system to its output. In the testing phase, the neural network should predict the correct system output for a given input, even if the input was not used in training. Here for generality, the scalar weighted summing of the input array $x i$ is distorted by a linear function $\varphi($.$) which is usually sigmoidal (e.g. tanh function) to$ facilities the gradient search techniques used in the training procedure. An Adaptive Neural Networks (ANN) is made up of many such neurons arranged in a variety of architectures. The feed-forward architecture graph show in "Figure 4 ", offers the advantage of simplicity and ease of programming.

\subsection{Training Neural Network}

The most common method of neural network is error back-propagation algorithm (Kuchar, Brandstetter et al. 2004). The algorithm is based on the gradient descent search technique that minimizes a cost function of the mean square errors. The minimization process is done by adjusting the weighting vector of the neural network. Several training algorithms have been proposed to adjust the weight values in dynamic recurrent neural network. Examples for these methods are the dynamic back-propagation from (Narendra and Parthasarathy,1991; Narendra, 1996; ); among others. The cost function being minimized is the error between the network output and the desired output given by equation (11):

$$
E=\frac{1}{2} \sum_{j} e_{j}^{2}(k)=\frac{1}{2} \sum_{j}\left[y_{j}^{*}-y_{j}(k)\right]^{2}
$$


where $y_{j}(k)$ is the output of neuron $\mathrm{j}$ and $\mathrm{y}_{\mathrm{j}}^{*}(\mathrm{k})$ is the desired pattern for that neuron. Let $\eta_{\mathrm{ji}}(\mathrm{k})$ denote the learning rate parameter assigned to synaptic weight $\mathrm{w}_{\mathrm{ji}}(\mathrm{k})$ at iteration number k. Minimizing equation (12) leads to a sequence of update of weight vector. The weights of the interconnections between two adjacent layers can be update based on the following formula (12):

$$
\mathrm{w}_{\mathrm{ji}}(\mathrm{k}+1)=\mathrm{w}_{\mathrm{ji}}(\mathrm{k})-\eta_{\mathrm{ji}}(\mathrm{k}+1) \frac{\partial \mathrm{E}(\mathrm{k}, \mathrm{w})}{\partial \mathrm{w}_{\mathrm{ji}}(\mathrm{k})}+\alpha \Delta \mathrm{w}_{\mathrm{ji}}(\mathrm{k})
$$

$\alpha$ is the momentum gain, is susceptible to local minima and needs additional computation for gradient evaluation, and $\Delta \mathrm{w}_{\mathrm{ji}}(\mathrm{k})$ is weight change based on gradient of the cost function $\mathrm{E}_{\mathrm{k}, \mathrm{w}}$ and $\mathrm{k}$ is the iteration number.

\subsection{Adaptation Learning Control Scheme}

The proposed adaptive neural network controller is shown in "Figure 6". where as the structure of the neural network used is featured in "Figure 7". In off line training the targets are provided by an existing controller, the neural network adjusts its weights until output from the ANN is similar to the controller.

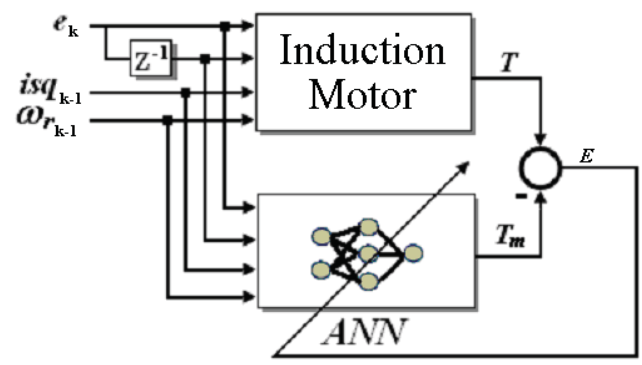

Fig. 6. Supervised learning using an existing controller

The four input signals $(\mathrm{e}(\mathrm{k}), \mathrm{e}(\mathrm{k}-1)$, isq( $\left.\mathrm{k}-1), \mathrm{w}_{\mathrm{r}}(\mathrm{k}-1)\right)$, and the torque $(\mathrm{T}(\mathrm{k}))$ output are exported to the MATLAB Workspace. The following MATLAB code trains the Neural Network. The first section of code generates the 'cell array'. The cell array combines the 4 different inputs into 1 input vector. 


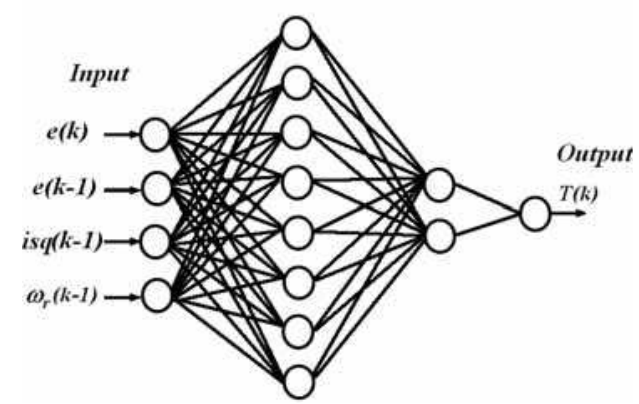

Fig. 7. Multilayer Feed-forward Neural Network.

The Feed-forward network has 10 neurons in the two layers "Figure 7". The activation function in the two layers is tan-sigmoid and the output layer is a linear function.

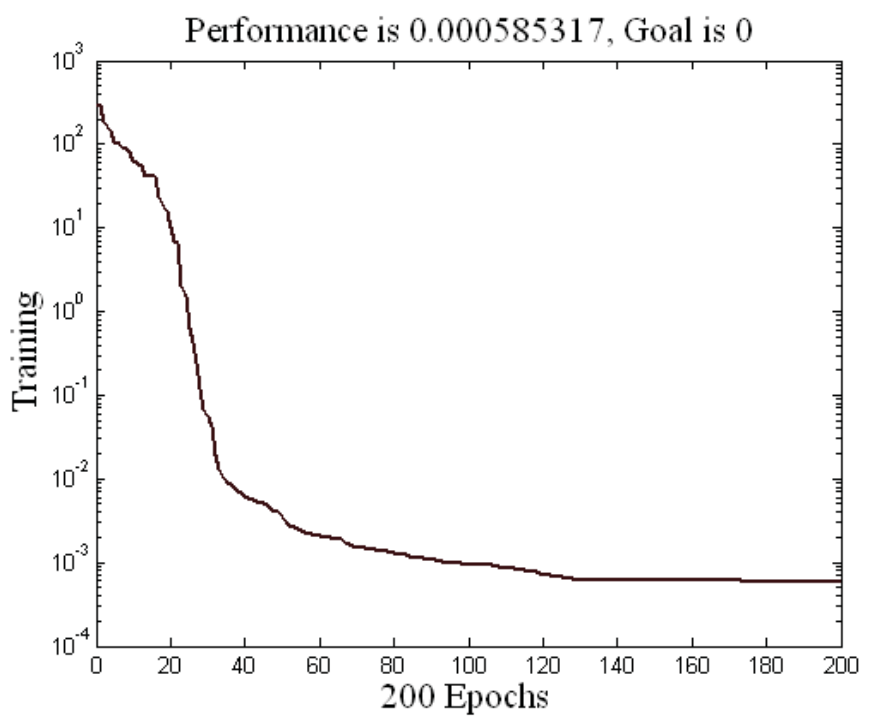

Fig. 8. Training error.

where the training is finished, the weights are set "Figure 8 ", and a simulink ANN is generated. The network is placed in the existing PI controller in the block diagram of indirect oriented field vector controlled ("Figure 9"). 


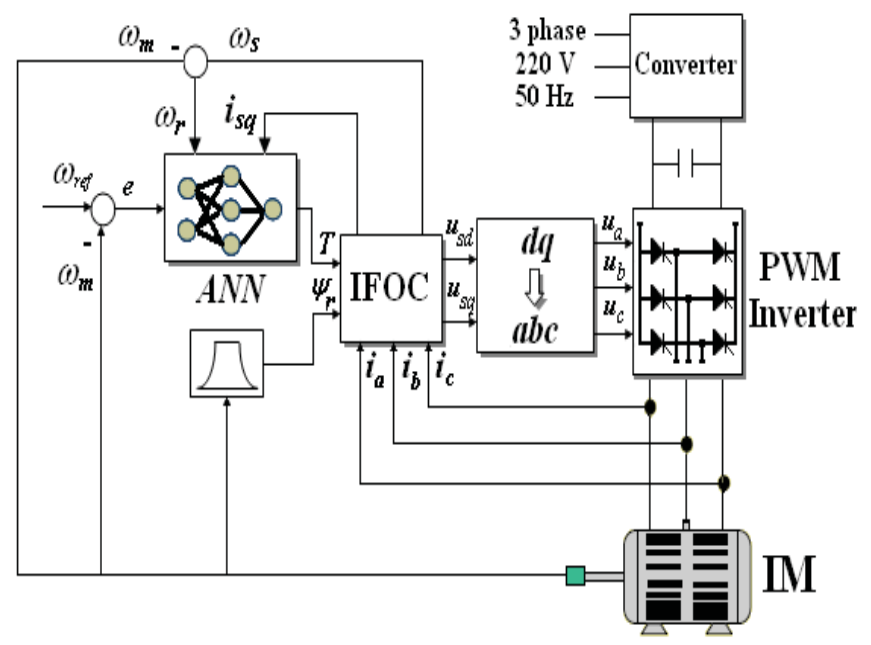

Fig. 9. Vector drive with ANN based feedback signal processing

\section{Results and discussion}

The vector controller induction motor drive using artificial neural network was simulated trough Matlab-software with simulink toolboxes. The simulation phase was very important to verify correctness of theoritical assumptions and to find behaviour of the drive. The parameters values of the system under study are summarized in "Table 1".

\begin{tabular}{|c|c|c|c|}
\hline Rated values & Power & 1.5 & $\mathrm{~kW}$ \\
\hline & Frequency & 50 & $\mathrm{~Hz}$ \\
\hline & Voltage $\Delta / \mathrm{Y}$ & $220 / 380$ & $\mathrm{~V}$ \\
\hline & Current $\Delta / \mathrm{Y}$ & $11.25 / 6.5$ & $\mathrm{~A}$ \\
\hline & Motor Speed & 1420 & $\mathrm{rpm}$ \\
\hline & pole pair $(\mathrm{p})$ & 2 & \\
\hline Rated parameters & $\mathrm{Rs}$ & 4.85 & $\Omega$ \\
\hline & $\mathrm{Rr}$ & 3.805 & $\Omega$ \\
\hline & $\mathrm{Ls}$ & 0,274 & $\mathrm{H}$ \\
\hline & $\mathrm{Lr}$ & 0,274 & $\mathrm{H}$ \\
\hline & $\mathrm{M}$ & 0,258 & $\mathrm{H}$ \\
\hline Constants & $\mathrm{J}$ & 0,031 & $\mathrm{Kg} \cdot \mathrm{m}^{2}$ \\
\hline & $f$ & 0,00114 & $\mathrm{Kg} \cdot \mathrm{m} / \mathrm{sec}$ \\
\hline
\end{tabular}

Table 1. Rating of tested induction motor

The proportional and derivative parameters of the proposed control scheme are $K_{p}=0.58$ and $K_{i}=11.19$. Several test cases were considered in order to evaluate the performances under a 
variety of operating conditions. For the robustness of the proposed control scheme, we assure that the parameters of rotor resistance $\mathrm{Rr}$ and load inertia J have been perturbed from their nominal values "Figures.10,11". The parameters of stator resistance, inductances and viscous friction their nominal values. It is evident that the speed response of the proposed control scheme is not significantly affected by this variation. One can see from these all figures the results were very successful and the obtained results confirm the validity of the proposed control scheme.

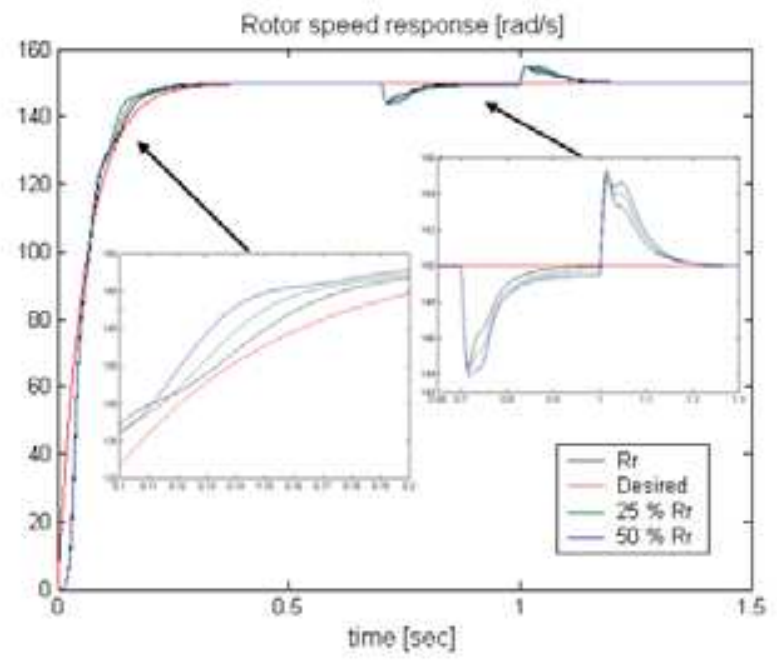

Fig. 10. Results of speed evolution after resistance changes.

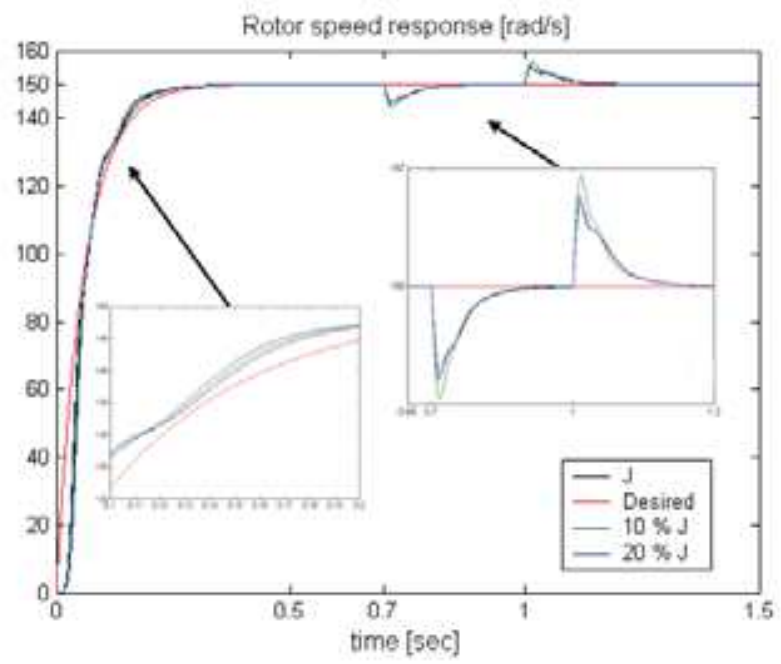

Fig. 11. Results of speed evolution after inertia load changes. 

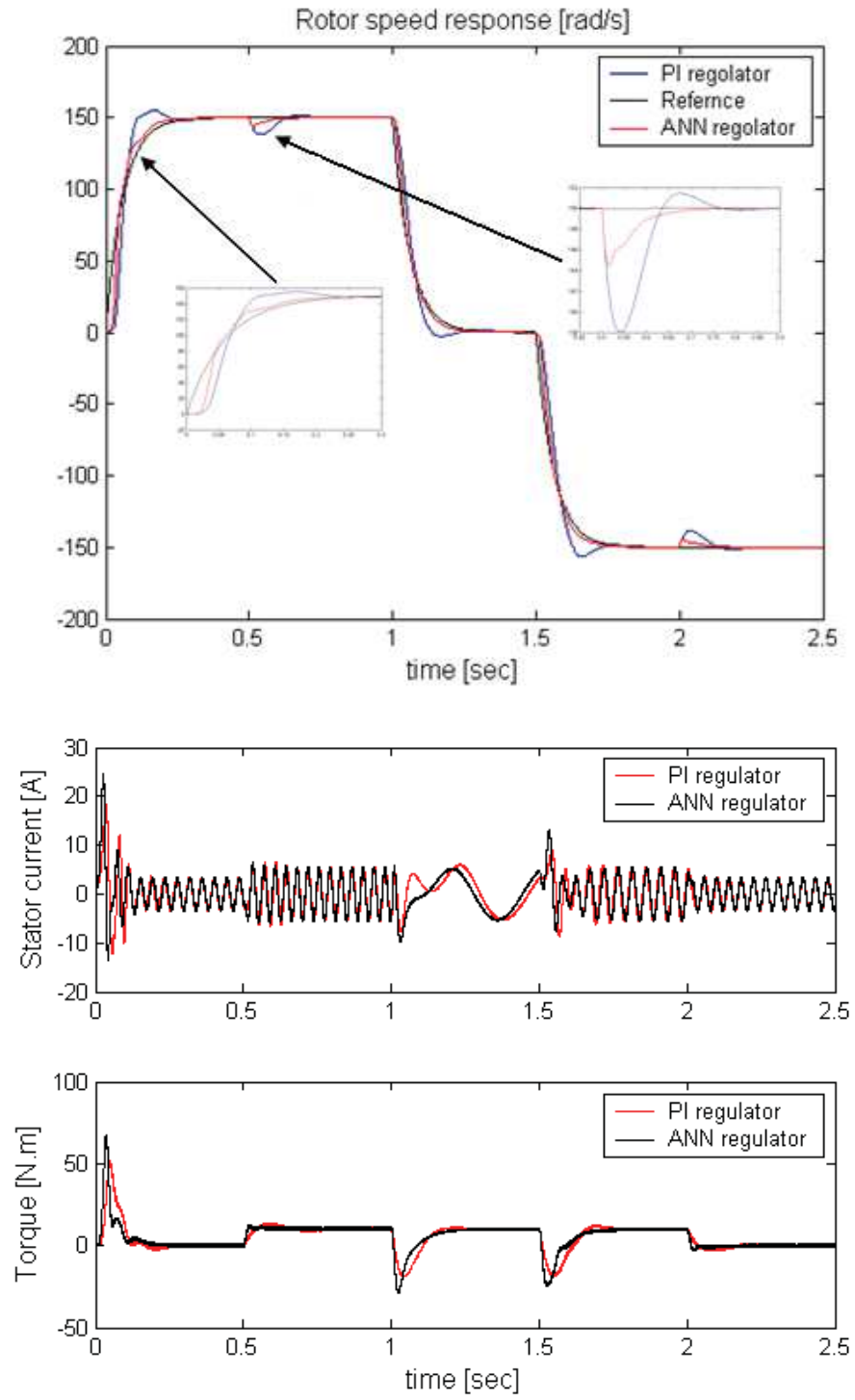

Fig. 12. Speed control system using neural controller and PI controller

"Figure 12" shows the behaviour of the system to screw of resistant torque $T_{1}=10$ N.m, his disturbance can be seen at $\mathrm{t}=0.5 \mathrm{sec}$ and $\mathrm{t}=2 \mathrm{sec}$, in maintaining the constant speed control $\omega_{\mathrm{r}}=150 \mathrm{rad} / \mathrm{sec}$ and $\omega_{\mathrm{r}}=-150 \mathrm{rad} / \mathrm{sec}$ at $\mathrm{t}=1.5 \mathrm{sec}$. "Figure 13" shows the results by Reference without filter, the results were very successful and the obtained results confirm the validity of the proposed controller. To demonstrate the robustness of the proposed controller, "Figure 14" displays the results of speed control using neural controller with stochastic lead change, the neural controller reduces both the overshoot and extent of oscillation under the same separating condition. 

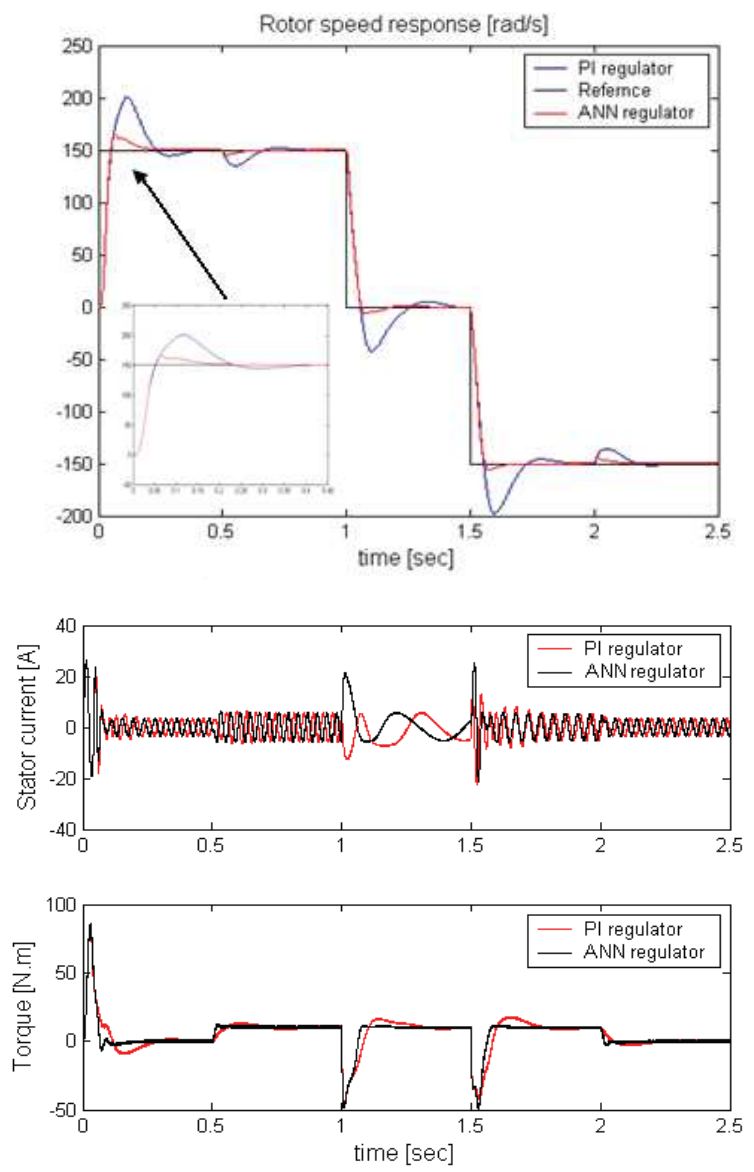

Fig. 13. Speed control system using neural controller and PI controller

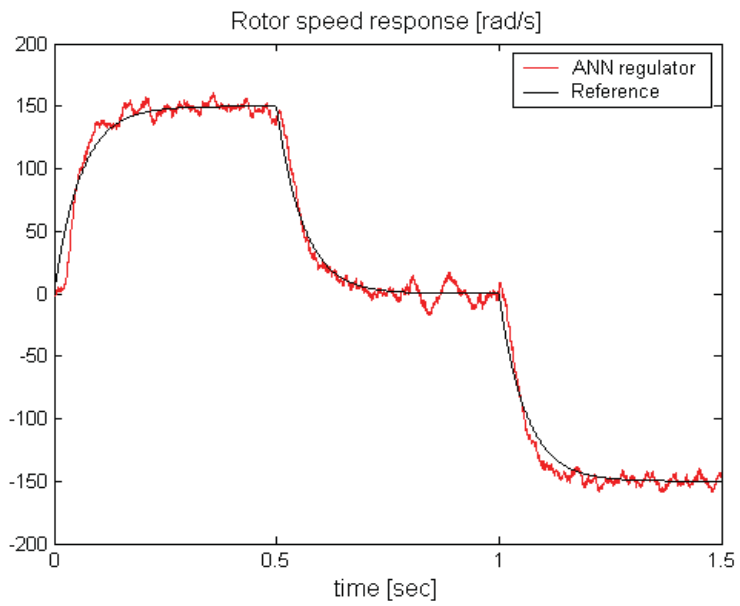



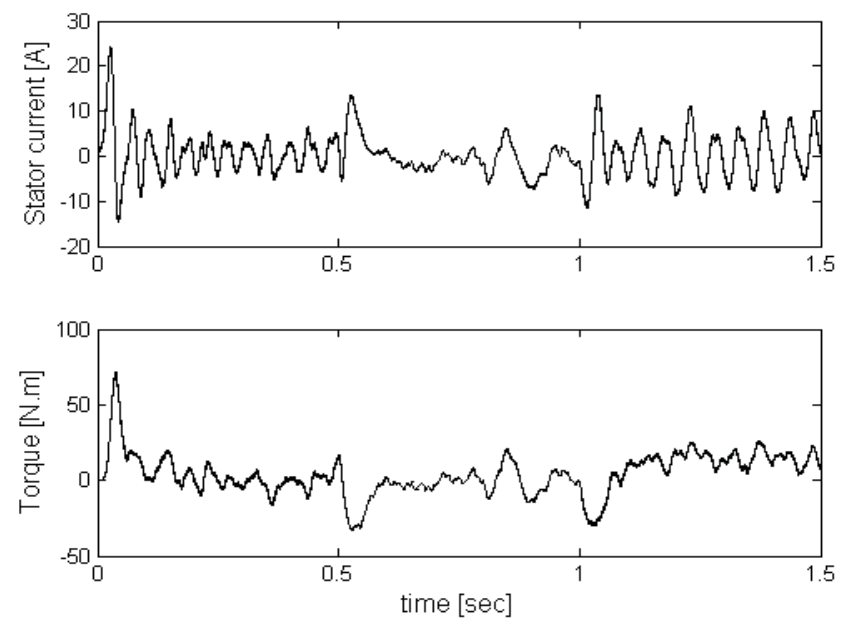

Fig. 14. Speed control using neural controller with stochastic lead change.

\section{Concluding remarks}

In this paper, we have designed and implemented the neural network controller NNC, for accurate speed control of an induction motor. Comparing PI-type control method, simulation results are provided to illustrate the performance and the effectiveness of the proposed control scheme, even in the presence of much strong mechanical fiction and other non linear characteristics. The success of the designed controller is demonstrated in realtime under load conditions by applying a load torque to the shaft of the motor. The results show that the controller could compensate for this kind of disturbances. The plant is also tested for the tracking property using different types of reference signals. Satisfactory performance was observed for most reference tracks and the results demonstrated the effectiveness of the proposed structure and the proposed control scheme it is believed will constitue a major step in the evolution of intelligent control of complexe mechatronic systems.

\section{References}

Liaw, C.M., Kung, Ys. \& Wa, C.M., (1991). Design and implementation of a hight performance field-oriented induction motor drive. IEEE. Trans. Ind. Electron. Vol. 38 , No. 4, pp. 275-282.

Zhang, J. Thiagarajan, V., Grant, T. \& Barton, T.H. , (1988).New approach to field orientation control of a CSI induction motor drive, Electric Power Applications, IEE Proceedings B, Vol. 135, No 1,pp. 1-7.

Pillay, P. \& Krishnam, R., (1988). Modelling of permanent magnet motor drive. IEEE Trans. Ind. Electronics. Vol. 35, No. 4, pp. 537-541.

Tien-Chi, C. \& Tsong-Terng, S., (2002). Model reference neural networkcontroller for induction motor speed control. IEEE Transaction on Energy Conversion, Vol. 17, No 2, pp. 157-163. 
Chen, T.C. \& Sheu, T. T., (1999). Robust Speed- controlled Induction-motor Drive Based on Model Reference with Neural Network, International Journal of Knowledge-Based Intelligent Engineering Systems, Vol. 3, No 3, pp. 162-171,

Narendra, K.S., (1996). Neural networks for control theory and practice, Proceedings of the IEEE, Vol. 84, No. 10, pp. 1385-1406.

Kuchar, M. Brandstetter, P. \& Kaduch,M., (2004). Sensorless induction motor drive with neural network, Power Electronics Specialists Conference, 2004. PESC 04. 2004 IEEE 35th Annual, Vol. 5, pp. 3301- 3305.

Narendra , K.S. \& Parthasarathy, K., (1991). Gradient methods for the optimization of dynamical systems containing neural networks, IEEE Transactions on Neural Networks, Vol. 2, No 2, pp. 252-262.

Oh, W.S. Cho, K.M. Kim, S. Kim, H.J., \& Yuhan C., (2006). Optimized neural network speed control of induction motor using genetic algorithm, International Symposium on Power Electronics, Electrical Drives, Automation and Motion, SPEEDAM 2006. pp: 1377-1380.

\section{Biography}

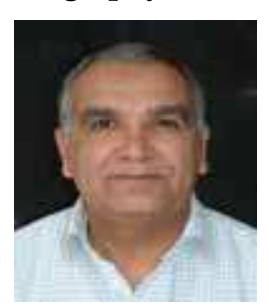

Zerikat $\left(\mathrm{M}^{\prime} 05\right)$ received the B.S degree in electrical engineering and the M.S. and Ph.D degrees in electronics from the University of Sciences and Technology of Oran, Algeria, in 1982, 1992, and 2002, respectively. Following graduation, he joined the university as a lecturer. He is currently a professor in the department of electrotechnics engineering He is engaged in research and in education in the area of electrotechnics. Actually he is associate Professor at Electrical Engineering Institute (ENSET) of Oran- Algeria. His current research includes electrical machines, High-performance motor drives, modelling and adaptive control systems, image processing and development intelligent applications. He is actively involved in many projects with industry while engaged in teaching, research and consulting in the area of artificial intelligence. Actually, he is associate Professor at the department of electrical engineering (ENSET) of Oran in Algeria. He has authored more than 60 technical papers published in international journals and conferences proceedings. He authored a book on automatic Control, which was recently was published and regularly gives tutorials and industrial courses on these subjects.

Dr. Zerikat is a chairman of the institute of electrical and electronic engineers in the Algeria state. He is regularly reviews papers for several journals in his area. He is an active member of the industrial COST Education Committee.

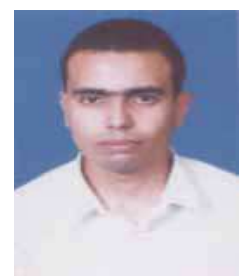

Soufyane Chekroun was born in Tlemcen, Algeria, in 1983 He received his B.S and M.S degrees in Electrical Engineering from the University of Sciences and Technology of Oran, Algeria.

Following graduation, he joined the Institute of Electrical Engineering of ENSET Oran, Algeria, as a research $h$ associate. His current research interests. His research interests include Electrical machines and development of intelligent applications ( fuzzy logic and neural networks) and the practical developments of high performance electrical motor derives and their related knowledge control schemes. 


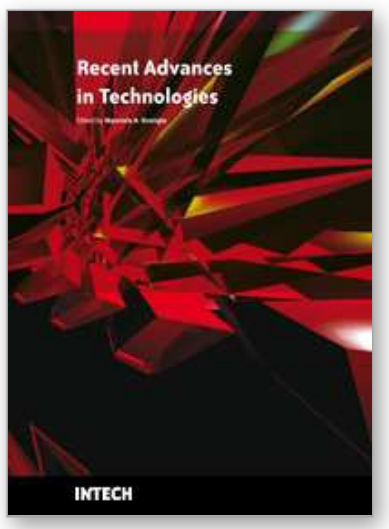

\author{
Recent Advances in Technologies \\ Edited by Maurizio A Strangio
}

ISBN 978-953-307-017-9

Hard cover, 636 pages

Publisher InTech

Published online 01, November, 2009

Published in print edition November, 2009

The techniques of computer modelling and simulation are increasingly important in many fields of science since they allow quantitative examination and evaluation of the most complex hypothesis. Furthermore, by taking advantage of the enormous amount of computational resources available on modern computers scientists are able to suggest scenarios and results that are more significant than ever. This book brings together recent work describing novel and advanced modelling and analysis techniques applied to many different research areas.

\title{
How to reference
}

In order to correctly reference this scholarly work, feel free to copy and paste the following:

Mokhtar Zerikat and Soufyane Chekroun (2009). Adaptation Learning Control for a H-P Induction Motor using Neural Networks, Recent Advances in Technologies, Maurizio A Strangio (Ed.), ISBN: 978-953-307-017-9, InTech, Available from: http://www.intechopen.com/books/recent-advances-in-technologies/adaptationlearning-control-for-a-h-p-induction-motor-using-neural-networks

\section{INTECH}

open science | open minds

\section{InTech Europe}

University Campus STeP Ri

Slavka Krautzeka 83/A

51000 Rijeka, Croatia

Phone: +385 (51) 770447

Fax: +385 (51) 686166

www.intechopen.com

\section{InTech China}

Unit 405, Office Block, Hotel Equatorial Shanghai

No.65, Yan An Road (West), Shanghai, 200040, China

中国上海市延安西路65号上海国际贵都大饭店办公楼405单元

Phone: +86-21-62489820

Fax: $+86-21-62489821$ 
(C) 2009 The Author(s). Licensee IntechOpen. This chapter is distributed under the terms of the Creative Commons Attribution-NonCommercial-ShareAlike-3.0 License, which permits use, distribution and reproduction for non-commercial purposes, provided the original is properly cited and derivative works building on this content are distributed under the same license. 